\title{
Research as a transformative experience
}

\author{
Margaret Walshaw
}

Published online: 27 October 2013

(C) Springer Science+Business Media Dordrecht 2013

Research with teachers should be transformative. When research is a transformative experience, it leaves all those involved in it better than when they started. But life experiences are not always transformative. Recently, I found myself bearing witness to the struggles and challenges that a prospective teacher was facing in her practicum experience. As I was shuttled back and forth to hear the perspective of the school and that of the prospective teacher, it was clear that, as an educator, my role was to mediate the situation and attempt to arrive at a solution. But what is the role of the researcher in a similar context? What role does the researcher play when confronted with inequitable practices and opportunities? How many of us embrace that question, not only in our thoughts, but also in our actions, our projects, and commitments? How many of us open the door to the possibility that what we do in the name of research might be otherwise?

There is something distinctly telling about our work within the rarefied halls of the academy. For many of us researching within mathematics education, the question concerning what to do about inequities is often eclipsed by other more pressing concerns. Many of us (myself included) are often so keenly focused on keeping up to date in our own specific area of interest, accomplishing our institution's goals, and complying with institutional regulations that the urgency of the larger question tends to escape us. We sacrifice an engagement with the big issues in order to preserve the integrity of our place within the academic arena. The irony is, of course, that we all know that academic work within mathematics education needs to be linked with the practice-based work of teachers. An engagement with the larger questions that animate our research might well make the connections between theory and practice happen.

Such an engagement might begin by honoring the central role and influence the teacher has on students' learning and life chances. Honoring the work of teachers has the effect of shifting the orientation off ourselves as researchers who have knowledge and toward the teachers. Resonating with the practices that have been shown to characterize effective teaching, the researcher becomes attentive to the teacher and engages in purposeful

M. Walshaw ( $\square)$

Massey University, Palmerston North, New Zealand

e-mail: m.a.walshaw@massey.ac.nz 
listening-listening not simply to those teachers with whom she agrees but also to those holding divergent viewpoints. She develops a sensitivity to the cognitive demands of teaching. The questions she asks and the dialog through which she is engaged with teachers are grounded in a respect of the other. It is a respect that carries over to those aspects of classroom life that envelop the teacher's work: a respect for the curricular, structural, and management choices made by teachers as well as their decisions concerning the material infrastructure that provide students with opportunities to learn.

The researchers whose work is reported in this issue of the Journal of Mathematics Teacher Education all demonstrate a respect for the teachers who share an intellectual space with them during their projects. In "An Investigation of Prospective Secondary Mathematics Teachers' Conceptual Knowledge of and Attitudes towards Statistics," the authors, Ailish Hannigan, Olivia Gill, and Aisling Leavy had teachers' interests keenly at heart. The starting point for the research they carried out was in the realization that the current push for statistical literacy places new and heavy demands on teachers. They wanted to know about Irish teachers' conceptual understanding of and attitudes toward statistics. They then sought to explore the relationship between teachers' knowledge and their attitudes. Using a standard assessment instrument to gauge statistical understanding and employing a widely used instrument to ascertain attitudes toward statistics, the authors recruited 134 prospective secondary school mathematics teachers, all of whom had chosen mathematics as an elective subject. Most of these teachers were enrolled in a 4-year Physical Education undergraduate program and were at different stages in the program. Entry into this program is based on high achievement, including mathematical achievement, at the school level. A further 19 participants in the study were enrolled in a 1-year graduate diploma program in education (mathematics teaching). All participants in the study recorded positive attitudes toward statistics, with the postgraduate students demonstrating the most positive attitudes. However, all students demonstrated poor understanding in a number of key areas of statistics.

The use of standard instruments within the study made it possible for the authors to compare their results with available findings involving students from other disciplines. Comparing their findings, they noted that their mathematically able prospective teachers did not record a higher level of understanding of statistics than students with strengths in other disciplines. From that, they conclude that mathematical thinking and statistical thinking are quite different entities and that strengths in mathematics are not necessarily an indicator of strengths in statistics. They note that while mathematical thinking focuses on abstract patterns, statistical thinking involves interpretation and critical judgment. The assumptions that underpin statistical thinking may be in conflict with those grounding mathematical thinking, to the extent that statistical ideas may appear to be counterintuitive. They also found that positive attitudes toward statistics do not always imply an aptitude with statistics.

In honoring the key role that pedagogical content knowledge plays in the teacher's practice, John Lannin, Matthew Webb, Fran Arbaugh, Kathryn Chval, Sarah Hicks, Cynthia Taylor, and Rebecca Bruton explored "The Development of Beginning Mathematics Teacher Pedagogical Content Knowledge" (PCK) for two prospective middle school male teachers. In the authors' explanation, PCK includes knowledge of: curriculum for mathematics; instructional strategies for mathematics; assessment for mathematics; and student understanding within mathematics. The two participant students were enrolled in a postgraduate 15-month program designed for students with a strong mathematical background. The program was structured to allow for $20 \mathrm{~h}$ teaching per week during the first year within a supportive school environment and, specifically, with the assistance of a 
mentor teacher. Both students then completed their certification program over the summer period before employment as beginning teachers within two middle schools.

Using data collected from an instructional planning task undertaken at the beginning and end of the two-year prospective/beginning teacher period, the authors investigated pedagogical content knowledge in accordance with their chosen framework. They also interviewed the mentor teachers and, with the two students, used stimulated recall interviews, developed from observations, field notes, and video diaries to explore specific aspects of PCK. Findings reveal that the pedagogical content knowledge of the two students was enhanced over the 2-year period but in varying forms, despite the fact that their teacher preparation opportunities had been similar. For one student, a focus on assessment contributed to a development of knowledge of student understanding and instructional strategies to a greater extent than to a development of his knowledge of curriculum. The other student significantly enhanced his knowledge of curriculum, but the development of his knowledge of assessment, student understanding, and instructional strategies was limited. He made connections among units of work and student levels, and while he planned for inquiry lessons, his instructional strategies limited his effectiveness in engaging students in inquiry processes. The findings draw attention to the importance of providing a range of opportunities for the development of the multiple aspects of pedagogical content knowledge.

In keeping with a respect for teachers, Michael Steele, Amy Hillen, and Margaret Smith developed a teaching experiment that incorporated sustained opportunities for teachers' learning. Their work enhances our understanding of the ways in which teacher knowledge emerges. In "Developing Mathematical Knowledge for Teaching in a Methods Course: The Case of Function," they tracked how prospective and practicing secondary school teachers enhance their common content knowledge (CCK) and specialized content knowledge (SCK). Mindful of the limitations of professional development opportunities that are content-general and episodic, the authors developed their initiative with the expressed purpose of focusing on one content area-function-over a 6-week period. Designed to enhance teachers' capacities to plan, select meaningful tasks, and assess student work and thinking, the course was organized for the teachers, with varying levels of experience, to meet $3 \mathrm{~h}$ twice a week through the summer term.

From past research findings, the authors identified key concepts relating to the notion of function and then used those concepts as organizers for their CCK and SCK categories and to track growth. During the course, the teachers solved rich mathematical tasks by sharing and evaluating alternative pathways, from a learner's perspective. They then explored the task from a teacher's perspective. Throughout the course, the authors collected data from a range of sources including interviews with each teacher at the beginning and end of the course, pre- and post-written assessments of key mathematical and pedagogical concepts, video clips of the discussions within the course, instructional artifacts, and copies of teachers' work. The 21 graduate teachers in the course began with different understandings of function, yet over the course of teaching experiment, all teachers demonstrated an enhanced understanding of the nature of function and its varied representations and were able to apply that knowledge to teaching. The teachers particularly valued the opportunity to engage with the tasks from both a learner's and a teacher's perspectives. They identified the sequence of solving tasks from a learner's perspective, sharing solutions with the other teachers, and then analyzing the task from a teacher's perspective as an important feature of the course and as a catalyst for their professional growth.

Just as the authors whose work is reported in this issue have done, we need to engage with the realities of teaching. It is not about research for its own sake, and it is not about us 
and them. Rather, it is about an ethical obligation to the teachers in our projects. And it is about developing respect for the difficult work they do in classrooms. Only then might we be able to offer a truly transformative experience. 